\title{
EL CASÓN DEL BUEN RETIRO Y LA EXPOSICIÓN CENTENARIA DE ALONSO BERRUGUETE EN 1961: CULTURA Y PROPAGANDA ENTRE ESPAÑA, EUROPA Y AMÉRICA LATINA
}

\author{
Tommaso Mozzati ${ }^{1}$ \\ Università degli Studi di Perugia
}

\begin{abstract}
A la luz de documentos inéditos, el artículo examina la muestra conmemorativa de la obra de Alonso Berruguete que organizó la Dirección General de Bellas Artes en 1961 en el Casón del Buen Retiro de Madrid. Desde esta perspectiva se analiza la relevancia política que el gobierno franquista atribuyó a la programación cultural de ese espacio recientemente restaurado, y los esfuerzos diplomáticos realizados para dar a conocer el evento en Europa y en América Latina, ofreciendo una visión ideológica del arte del escultor castellano, útil para la propaganda cultural del régimen.
\end{abstract}

Palabras clave: Alonso Berruguete; Casón del Buen Retiro; exposiciones; franquismo; política cultural; hispanidad; América Latina.

\section{THE CASÓN DEL BUEN RETIRO AND THE ALONSO BERRUGUETE CENTENNIAL EXHIBITION} IN 1961: CULTURE AND PROPAGANDA BETWEEN SPAIN, EUROPE AND LATIN AMERICA

In light of several unpublished documents, this article examines the 1961 centennial exhibition organized by the Dirección General de Bellas Artes and held at the Casón del Buen Retiro in Madrid, which was dedicated to Alonso Berruguete. In doing so, it analyzes the political relevance attributed by the Francoist government to the cultural program hosted in that recently restored building as well as the diplomatic efforts made to publicize the Berruguete show in Europe and Latin America, offering an ideological vision of the art of the Castilian sculptor and of its usefulness for the cultural propaganda of the regime.

Key words: Alonso Berruguete; Casón del Bue Retiro; exhibitions; francoism; cultural policy; Spanishness; Latin America.

Cómo citar este artículo / Citation: Mozzati, Tommaso (2021) "El Casón del Buen Retiro y la exposición centenaria de Alonso Berruguete en 1961: cultura y propaganda entre España, Europa y América Latina”. En: Archivo Español de Arte, vol. 94, núm. 375, Madrid, pp. 281-296. https://doi.org/10.3989/aearte.2021.17.

Tras las renovaciones llevadas a cabo por Víctor d'Ors a partir de 1959, el Casón del Buen Retiro vio reconvertida su función original de sede del Museo de Reproducciones Artísticas a la de espacio reservado para un ambicioso programa de exposiciones temporales. ${ }^{2}$ Así pues, el edificio, construido hacia 1637 por encargo de Felipe IV, pasó a tener un papel eminente para los objetivos propagandísticos de la dictadura franquista, ya entrada en su fase desarrollista bajo el control de

\footnotetext{
1 tommaso.mozzati@unipg.it / ORCID iD: https://orcid.org/0000-0002-3204-6463.

${ }^{2}$ Lorente Junquera, 1960.
} 


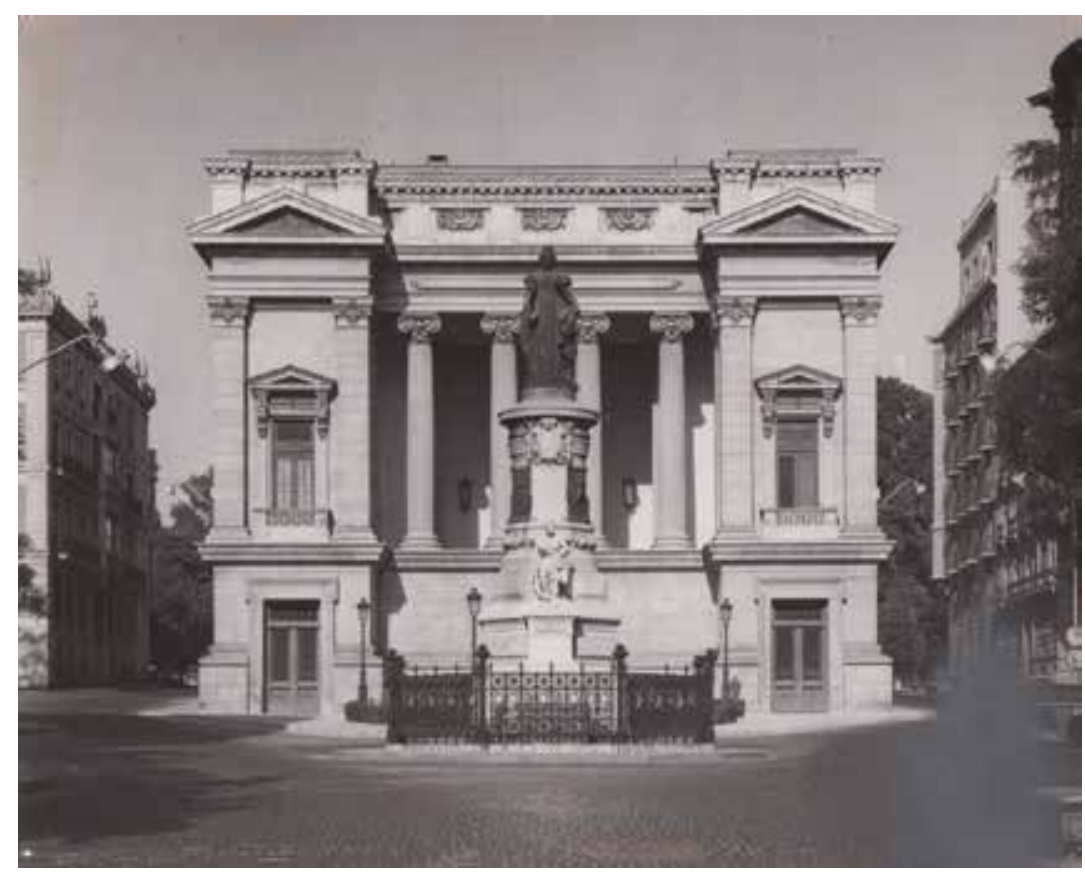

Fig. 1. Casón del Buen Retiro, Madrid.

los tecnócratas, respetando una función destinada a suscitar una amplia resonancia en la vida intelectual española.

El protagonismo que adquirió a nivel urbanístico gracias a las fachadas añadidas durante el siglo XIX se reflejaba ahora en el nuevo valor atribuido a estos espacios a nivel ministerial [fig. 1]. ${ }^{3}$ Sin embargo, el Casón fue administrado por la Dirección General de Bellas Artes, inaugurando un ajetreado calendario de iniciativas dirigidas a un público internacional. De hecho, desde principios de los años cincuenta se estaba experimentando una creciente pasión turística por los destinos ibéricos, una directa consecuencia del nuevo posicionamiento del gobierno en sus relaciones con Europa y Estados Unidos. ${ }^{4}$

Esta apertura también tuvo repercusiones a nivel de la promoción cultural y artística, orientada a una revisión de las tendencias tradicionalistas promovidas por el régimen desde los primeros años de su instauración a través del diálogo con los lenguajes de la Modernidad, en particular de la valorización de un 'camino español', orgánico (por decirlo así) a los desafíos de lo contemporáneo. $^{5}$

No es de extrañar, por tanto, que la primera de las exposiciones en el Casón estuviera dedicada a un protagonista absoluto del panteón artístico local, objeto desde el siglo XIX de un interés crítico y coleccionista compartido por un gran público de conocedores.

En consecuencia, el 10 de diciembre de 1960 se inauguró la muestra Velázquez y lo velazqueño con el fin de celebrar el tercer centenario de la muerte del pintor y atraer una masa cosmopolita de espectadores y amateurs [fig. 2].

Sin embargo, desde el título, la exposición pretendía presentar la lección del sevillano como una 'categoría' trans-histórica, para reconstruir un continuum de ascendencias e influencias. Aunque el itinerario se limitó a ilustrar la cadena de "predecesores", "maestros" y "discípulos directos" de Velázquez, la premisa del catálogo es cristalina al aclarar cuánto los comisarios habían tenido en cuenta "el ejercido de pintores no españoles [...], a donde llegó la acción ejemplar de

\footnotetext{
3 Chueca Goitia / Navascués Palacio, 2004.

${ }^{4}$ Véase, por ejemplo, Rosendorf, 2014.

5 Véase, por ejemplo, Marzo/Mayayo, 2015: 19-146.
} 


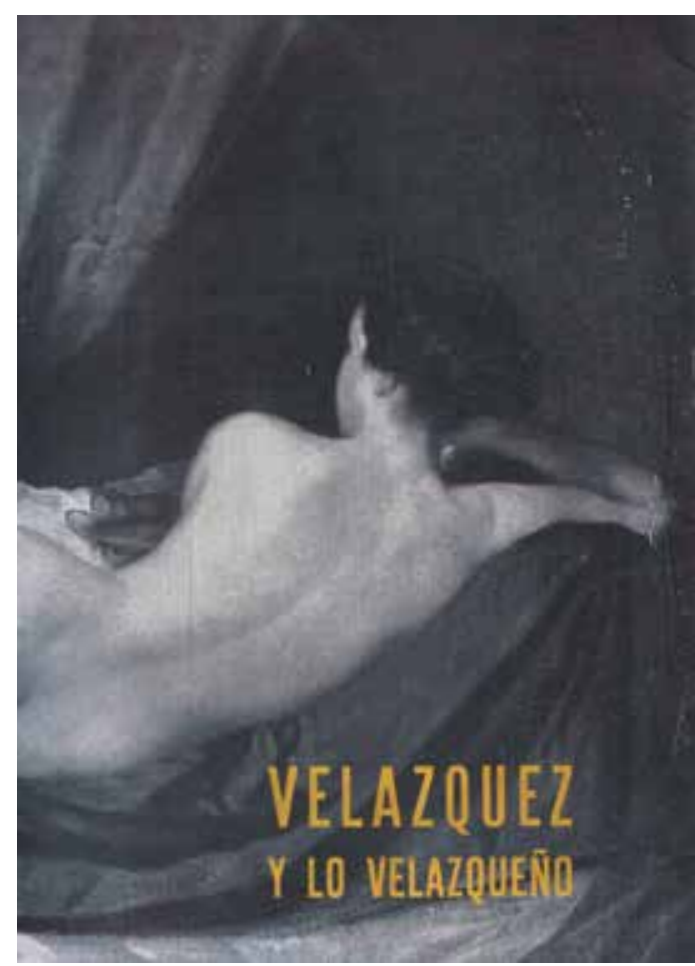

Fig. 2. Velázquez y lo velazqueño. Exposición homenaje en el III Centenario de su muerte. Madrid: Dirección General de Bellas Artes, 1960, portada del catálogo.

su pintura"; 6 y en este clima parece lógico que, casi en los mismos meses, se presentó en la galería Sala Gaspar de Barcelona un "homenaje informal" al artista, capaz de reunir a algunos de los nombres más famosos de la vanguardia nacional, desde un Antonio Saura hasta un Manuel Viola.?

Por lo tanto, es normal que el esfuerzo organizativo implicase el préstamo de renombradas colecciones extranjeras y de muchos museos de todo el mundo, desde Inglaterra hasta Estados Unidos, conllevando, en consecuencia, un despliegue diplomático y logístico sin precedentes en la posguerra española, al menos en lo que concierne al campo circunscrito de los Old Masters. Entre las excepciones más relevantes se puede mencionar la retrospectiva Goya montada en Venecia para la Bienal del 1952 y comisariada por Enrique Lafuente Ferrari (entonces Jefe de los Servicios Históricos y de Bellas Artes de Patrimonio Nacional), que movilizó a un número sustancial de prestadores internacionales, gracias también al apoyo del comité de expertos involucrado para planificar la Bienal, como por ejemplo Rodolfo Pallucchini y Roberto Longhi. ${ }^{8}$ Sin embargo, incluso este episodio, aunque significativo en términos de visibilidad, no compite realmente, en términos de financiación y de obras expuestas, con la muestra inaugurada en Madrid en diciembre 1960.

También hay que tener en cuenta que bajo la regencia ministerial del conservador Jesús Rubio García-Mina, nombrado después de Joaquín Ruiz-Giménez Cortés, ${ }^{9}$ el impulsor de la muestra titulada a Velázquez fue el entonces Director General de Bellas Artes, Antonio Gallego Burín, quien había caracterizado su mandato (cuyo inicio se remontaba a 1951) por una campaña dirigida a reubicar España en la agenda europea de los grandes eventos.

En este sentido, cabe destacar el Festival de Música y Danza Españolas, lanzado en 1952 en Granada (ciudad de la que era originario Gallego Burín y de la que había sido alcalde hasta 1951). Sin embargo, también se podría mencionar la movilización llevada a cabo en 1958 con motivo del centenario de la muerte de Carlos V. Para esta ocasión, el Director General preparó una grandiosa exposición bajo el título Carlos Vy su ambiente, motor de un masivo programa de iniciativas, desde la restauración del Hospital de Santa Cruz de Toledo hasta la de San Jerónimo de Yuste [fig. 3]. ${ }^{10}$

Es cierto que, si bien murió de cáncer el 13 de enero del 1961, la organización de la muestra en el Casón estuvo supervisada por Gallego Burín, quien ejercía un control total incluso desde la cama en la que acabó postrado durante las últimas semanas de vida. Por lo tanto, la responsabilidad del exorbitante presupuesto se debe a él completamente, dejando para los años siguientes

\footnotetext{
${ }^{6}$ Gallego Burín, 1960: 7.

7 Santos Torroella, 1960.

${ }^{8}$ Di Martino, 2005: 47. Véase también Bandera, 1999: 160-162.

9 Sobre Ruiz-Giménez Cortés y su actividad cultural véase Muñoz Soro, 2006: 262-270. Véase también JiménezBlanco, 2001: 511-516.

${ }^{10}$ Gallego Morell, 1973: 115-127; Viñes Millet, 2003: 143-156. Sobre la figura pública de Gallego Burín véase Hernández Burgos, 2011a; Hernández Burgos, 2011b.
} 


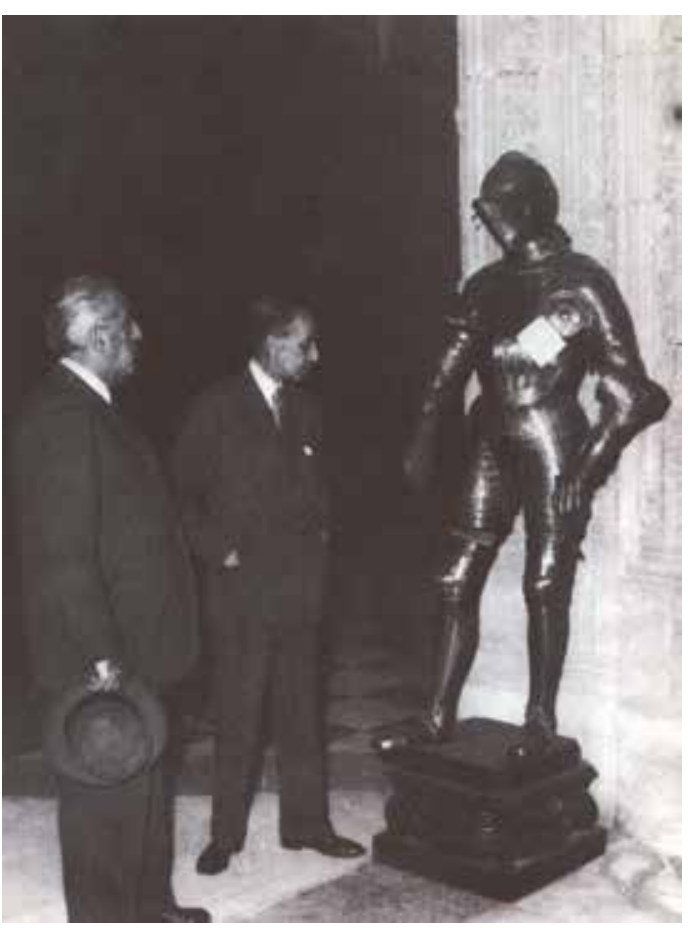

Fig. 3. Antonio Gallego Burín y Gregorio Marañón en la exposición Carlos Vy su ambiente, 1958. una sustancial secuela financiera que incluye la cobertura de más de seis millones y medio de pesetas de gasto total. ${ }^{11}$

Tras la muerte de Gallego Burín, fue designado como sucesor al frente de la Dirección General de Bellas Artes Gratiniano Nieto Gallo, cuya labor supuso una continuidad con la orientación dada por su predecesor a los espacios expositivos que habían acogido a Velázquez.

Una exposición dedicada a Goya sería inaugurada en el Casón ya el 28 de septiembre 1961, comisariada por Valentín de Sambricio, con el pretexto de celebrar el centenario de la capitalidad de Madrid y gracias a un repertorio de tesoros reunidos tanto de colecciones estatales como de las galerías aristocráticas españolas. ${ }^{12}$ La selección fue elogiada por la prensa, en particular por los periódicos más abiertamente progubernamentales. ${ }^{13}$ Sin embargo, para ponderar el valor político del proyecto conviene hacer referencia a las palabras que Juan Antonio Gaya Nuño publicó en Blanco y Negro: "A decir verdad, más congruente con el propósito hubiera sido una exposición de la buena y noble escuela madrileña del siglo XVII, pero ella puede tener efecto en cualquier otro momento, ahora que [...] ha sido destinado el Casón del Buen Retiro a sede de exposiciones. Las cuales, para [...] merecer éxito sin medida, no tienen por qué ajustarse a fechas jubilares [...] de nacimientos o muertes".${ }^{14}$ La institucionalidad de la programación asignada al Casón y estigmatizada con ironía por el artículo de Gaya Nuño justifica la enésima etapa de su calendario, que vino justo a continuación de la exposición de Goya, perfectamente acorde con las iniciativas que la anticiparon tanto en las premisas como en los propósitos conmemorativos.

En este sentido, pensemos en la exposición por el IV centenario de la muerte de Alonso Berruguete, encomendada por la Dirección General a la gestión de Consuelo Sanz-Pastor Fernández de Piérola, entonces directora del Museo Cerralbo y promotora de una ferviente renovación de las prácticas museísticas de ese instituto, relevante también a nivel nacional ${ }^{15}$ [fig. 4].

Es inequívoca la orden firmada el 6 mayo del 1961 por el Ministro García-Mina, para constituir el patronato del aniversario, destinado a una cartelera más amplia: "El IV centenario de la muerte del gran escultor Alonso Berruguete debe ser conmemorado con la solemnidad y realce debidos al significado que en el arte tiene tan prodigioso escultor". ${ }^{16} \mathrm{Y}$ no menos elocuentes son las declaraciones, firmadas por Nieto Gallo, contenidas en la nota introductoria al catálogo: "Si es cierto que una minoría conoce y valora [...] la obra de Berruguete, no es menos cierto que no es un artista po-

${ }^{11}$ Alcalá de Henares, Archivo General de la Administración (a partir de aquí AGA), caja 43165, carta del Ministro de Educación Nacional al Ministro del Tesoro, 8 octubre 1960; AGA, Caja 821818 obs. 880, Comité Ejecutivo de la Junta para la Conmemoración del III Centenario Velázquez, Acta, 26 marzo 1966.

12 De Sambricio, 1961.

${ }_{13}$ Izquierdo, 1961.

${ }_{14}$ Gaya Nuño, 1961: s. p.

15 Flores, 2005.

${ }^{16}$ AGA, 43165, carta del Director General de Bellas Artes al Ministerio de Educación Nacional, sin fecha; véase también Rubio García-Mina, 1961. 


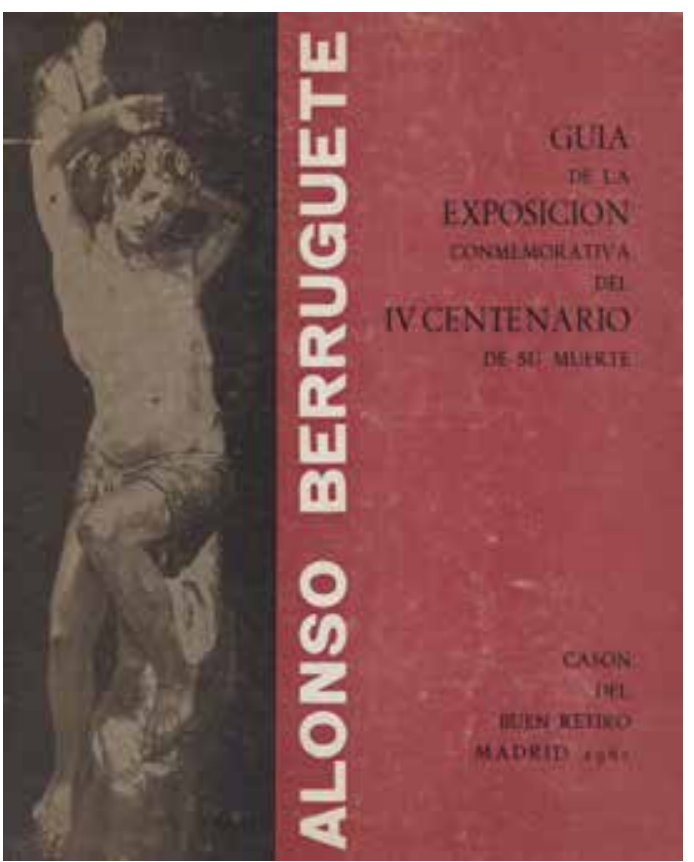

Fig. 4. Alonso Berruguete. Guía de la Exposición conmemorativa del IV Centenario de su muerte. Madrid:

Dirección General de Bellas Artes, 1961, portada del catálogo. pular al estilo de El Greco, Velázquez o Goya, y ello a pesar de que Berruguete en escultura, representa algo análogo a lo que en pintura representan los artistas citados". ${ }^{17}$ Por tanto, es evidente que el aniversario del escultor, natural de Paredes de Nava, se presentó a los ojos de las autoridades ministeriales como la ocasión perfecta para su consagración definitiva entre las glorias del canon español ${ }^{18}$ además, esta exhibición marcó un proceso que, durante el siglo XX, había resaltado su importancia para la historia artística del país, prefiriendo, entre las diversas miradas críticas enfocadas a lo largo de los años, la orientada a potenciar su aportación en términos de hispanidad oscura y candente, según las lecturas de firmas tan célebres como las de Eugeni d'Ors y Francisco de Cossío. Es decir, Berruguete era aclamado como un símbolo perfecto de la inextricable sinergia entre el elemento realista y el hecho espiritual, propio de la tradición ibérica. Además, su plasticidad exasperada se interpretaba a la luz de una parafernalia crítica que vinculaba el esperpento revelador de Valle-Inclán con el grotesco cargado de una moderna tradición tenebrista, desde las impresiones de viaje de Émile Verhaeren, a los colores bituminosos de José Gutiérrez-Solana, a los terribles inventos de Camilo José Cela. ${ }^{19}$

Bastará aquí citar un pasaje de la España negra de Solana, volumen publicado en 1920, que recoge recuerdos de viajes reales o ficticios, dedicando mucho espacio a una parada en Valladolid y a una visita al Museo Nacional de Escultura: "El sacrificio de Abraham y el San Sebastián [...] parecen raíces y enormes árboles centenarios; más que con gubia parece que están hechas a hachazos. [...] En las tallas de esta sala se ven desfilar todos los pasos de las procesiones de Semana Santa, con todo su realismo; [...], todo el arte dramático y trágico español" ${ }^{20}$ Precisamente tal línea, inclinada a identificar los datos formales como un símbolo indiscutible de pertenencia original, se adopta en las pocas páginas introductorias del catálogo: "[Berruguete] con fuerza arrastra a multitud de seguidores que [...] han da conservar como preciado patrimonio esa mezcla de realismo y espiritualidad tan característica del arte español. En esta expresividad radica su canon de belleza y, por ello, puede considerársele no sólo como antecedente del Greco, sino como antecedente del principio deformante moderno". Y, según una lógica bien enlazada, se traduce en un motivo de orgullo nacionalista y en un llamamiento a la mejora de tal expresión estatuaria en el marco de las políticas culturales del gobierno (y según la intención de Ramiro de Maeztu). ${ }^{21}$

Como prueba de este esquema propagandístico se puede enfatizar que un monumento aislado a Berruguete fue acometido precisamente en el 1961 con un retraso significativo en relación con las diversas propuestas formuladas entre 1913 y 1930, cuando se discutió en el Ayuntamiento de

${ }^{17}$ Nieto Gallo, 1961a: 11.

18 Álvarez Casado, 2003: 72-76.

19 Sobre esta recepción crítica véase la comunicación de Tommaso Mozzati por la jornada de estudios dedicada a Alonso Berruguete en la National Gallery of Art de Washington el 15 noviembre 2019, Celebrating Alonso Berruguete: Anniversaries, Monuments, Art History. Véase también Mozzati, 2021.

${ }^{20}$ Gutiérrez-Solana, 1920: 115-116.

${ }^{21}$ Sanz-Pastor, 1961b: 28-29. Véase tambien Álvarez Casado, 2003: 76-78. 
Palencia la financiación de una estatua que recordara al artista en su tierra natal. Sin embargo, fue solo con motivo del centenario que la puesta en marcha del grupo fue encomendada por una comisión nacional a Victorio Macho con destino a la plaza mayor de la ciudad castellana. La resonancia pública de este debate queda demostrada por el hecho de que una fuerte opinión pública había intentado evitar que la estatua llegase a su destino palentino (antes de la inauguración en diciembre de 1963), disponiendo que fuera enviada o bien a Madrid o bien Valladolid, lugares que parecían capaces de garantizar a la empresa una mayor resonancia. ${ }^{22}$

La propuesta de esta monográfica para el Casón también ofrecía el beneficio de una cierta simplificación organizativa. De hecho, la misma Sanz-Pastor - a quien se le confió la preparación a mediados de noviembre ${ }^{23}$ - recordó que el evento fue ordenado en el espacio corto de unas pocas semanas, apoyándose sobre todo en el patrimonio artístico regional, dada la concentración de la obra de Berruguete en las zonas de Valladolid y Toledo, así como en manos de unos particulares: "el Director General [...] me hizo de organizar una exposición conmemorativa del IV centenario de la muerte de Berruguete. Contábamos con muy poco tiempo, así que recorrí con mi Seiscientos las localidades en que estaba la obra del artista y, tras examinar su estado de conservación y posibilidad de exponerlas, Graciano Macarrón, quien me acompañaba en todo el viaje, tomaba las medidas [...] para llevar a cabo su posterior transporte e instalación". ${ }^{24}$

A juzgar por la lista de los expositores, publicada en catálogo, y por el inventario de las obras expuestas, se puede confirmar la reconstrucción de Sanz-Pastor. De hecho, la única institución extranjera en el registro es la Galería de los Uffizi, aunque es difícil determinar exactamente su contribución, ya que el museo no se menciona en ninguna otra página del volumen: probablemente el Gabinetto Disegni e Stampe otorgó algunos dibujos atribuidos a la mano del artista. ${ }^{25}$ Sin embargo, en este contexto, es posible comprender las razones de un gasto bastante limitado, que se enfrentó para coordinar el evento: el expediente del Ministerio de Educación Nacional de 18 octubre del 1961, apenas dos meses antes de la inauguración (celebrada el 18 diciembre siguiente), establece un presupuesto de 1.220 .000 pesetas. ${ }^{26} \mathrm{~A}$ pesar de ello, en comparación con el balance multimillonario de Velázquez, se pudieron presentar en Madrid "doscientas diez [piezas]" y "treinta y ocho atribuciones", reuniendo una rica galería del universo de las formas berruguetianas. ${ }^{27}$

Otro recuerdo de Sanz-Pastor genera nuevas preguntas. En un artículo entregado a la elegante revista Arte $=$ Hogar, la curadora afirma: "Al ser encargada de organizar esta exposición recorrí miles de kilómetros en busca de la obra de este singular artista, y me sorprendió contrastar la vivencia que aún hoy [...] tienen los arquetipos ideales plasmados por [...] Berruguete". ${ }^{28}$ De estas palabras parece claro que se decidió a atribuir la organización de la monográfica a un estudioso no especialista en el tema, en cumplimiento de las indicaciones dadas por la propia Dirección General (y en relación con una práctica usual); una iniciativa está que vinculaba el evento con las directivas ministeriales, subrayando su peso en términos de política cultural. De hecho, aunque las obras que se incluyeron en el itinerario fueron elegidas por la Comisión permanente designada en mayo con nombramiento ministerial, Sanz-Pastor se preocupó por el plan general del proyecto, dictando la lectura y las pautas oficiales. ${ }^{29}$

Significativamente, Valladolid habría sido recompensada por una programación autónoma, patrocinada por su alcalde, Santiago López González, y por el Centro de Estudios Castellanos, todavía en colaboración con las Bellas Artes. De este modo, entre el 9 y el 10 de febrero de 1962 se celebraron conferencias de José María de Azcárate, José Camón Aznar, Francisco de Cossío

22 Brasas Egido, 1987; Mena de la Cruz, 1999: 25-29, 35-52; Barrios Felipe, 2017.

23 AGA, caja 98475 obs. 689, carta del Director General al Jefe de la Sección Tesoro Artístico, 14 noviembre 1961.

${ }^{24}$ Flores, 2005: 180-181.

${ }^{25}$ Véase Sanz-Pastor, 1961a: 102. Véase tambien Nieto Gallo, 1961b.

${ }^{26}$ AGA, caja 98475 obs. 689, expediente del Ministerio de Educación Nacional, 18 octubre 1961.

${ }^{27}$ Nieto Gallo, $1961 b$.

28 Sanz-Pastor, 1962.

29 AGA, caja 98475 obs. 689, carta del Ministerio de Educación Nacional al Director General de Bellas Artes, 17 de octubre de 1961. 
y Federico Wattenberg (entonces director del Museo Nacional de Escultura), y se pronunció una misa solemne en la iglesia de Ventosa de la Cuesta. ${ }^{30}$ Una vez más, la clave para interpretar estas decisiones la ofrece Sanz-Pastor:

"La Dirección General [...] ha organizado una exposición antológica de la obra de nuestro genial imaginero Alonso Berruguete [...]. La exposición tiene lugar en el Casón del Buen Retiro madrileño, sitio apropiado - no por la estructura en sí del edificio, que pertenece a épocas posteriores de nuestra historia - , sino por el simbolismo que encierra este edificio regio, asentado en el corazón de España [...] hora era ya de que nuestro pueblo tributara a este insigne escultor el homenaje que le era debido por haber sabido encarnar cual ninguno la honda realidad y espiritualidad hispana". ${ }^{31}$

Por un lado, estas declaraciones justifican el mobiliario sobrio y claustral del Casón, documentado por las pocas fotografías - hoy conocidas - relativas a los días de la exhibición [figs. 5 y 6]; por otro lado, legitiman la presencia en la octava sala, entre el aparato ilustrativo, de una cartela dedicada a los "sucesos vividos por Alonso Berruguete", destinado a ilustrar los principales logros militares, estratégicos y culturales de la Corona de España ${ }^{32}$ [fig. 7].

Las afirmaciones de Sanz-Pastor también se reflejan en los comentarios contemporáneos de la prensa, en particular en los juicios de los periódicos más abiertamente institucionales. Sirva como comparación el artículo aparecido en La Vanguardia española, firmado por el escritor Manuel Pombo Angulo:

La presencia de Berruguete en Madrid [...] marca un hito muy importante en lo que pudiéramos denominar historia de nuestra sensibilidad. No cabe duda que, de tiempo a esta parte, dicha sensibilidad se ha extendido, invadiendo con su crecida zonas anteriormente sumidas en el más pertinaz de los secanos artísticos. En ello tiene mucho que ver ese mecenazgo, cada día más amplio también, ejercido por el Estado y que permite el contacto entre los grandes maestros de todas las edades y el pueblo de hoy. ${ }^{33}$

A la luz de este contenido ideológico se explican otras circunstancias, que se pueden conocer gracias a documentos inéditos, identificados en el Archivo General de la Administración.

La primera se refiere a un traslado de las obras de Berruguete a otro destino español, tras su exposición en Madrid. Cuando la muestra estaba a punto de clausurarse, se decidió planificar una presentación en Barcelona, enviando algunas de las piezas que aún se guardaban en la capital. Los primeros contactos entre el Ministerio de Educación Nacional y la Dirección General se iniciaron a mediados de marzo, señalando - como delegados para la nueva etapa - a Carlos Cid Priego, representante del Servicio de Defensa del Patrimonio Artístico, y Juan Ainaud de Lasarte, entonces director de los Museos de Arte de Cataluña. El evento iba a ser acogido en la capilla gótica de Santa Águeda, un espacio no tan majestuoso como el de Madrid, pero suficiente para albergar las esculturas elegidas para ser enviadas al sur, como la "Anunciación y Calvario de la Mejorada", el "San Sebastián" y el "Sacrificio de Isaac". ${ }^{4}$

Tal proyecto está relacionado con la cuarta exposición que habría ocupado los espacios del Casón durante el verano de 1962, especialmente porque esa misma fue comisariada por Cid Priego

30 Álvaro, 1962. Véase también "El IV centenario de la muerte de Berruguete". En: Hoja del Lunes, 12 febrero 1962, Barcelona, p. 2. Es significativo que por el tercer centenario de Velázquez se organizó una exposición-homenaje en Sevilla y se celebró una misa en sufragio el 6 agosto 1960; véase Hernández Díaz, 1960. Véase también III centenario de la muerte de Velázquez (1660-1960). Programa de Actos. Madrid: [sin editor], 1960, s. p.

31 Sanz-Pastor, 1962.

32 Sanz-Pastor, 1961a: s. p. (pero 110).

33 Pombo Angulo, 1961.

34 AGA, Caja 98475 obs. 689, carta del Ministerio de Educación Nacional al Director General de Bellas Artes, 14 marzo 1962; Carta del Director General de Bellas Artes al Jefe de la Sección de Tesoro Artístico, 14 marzo 1962. Véase también Perucho, 1962. 


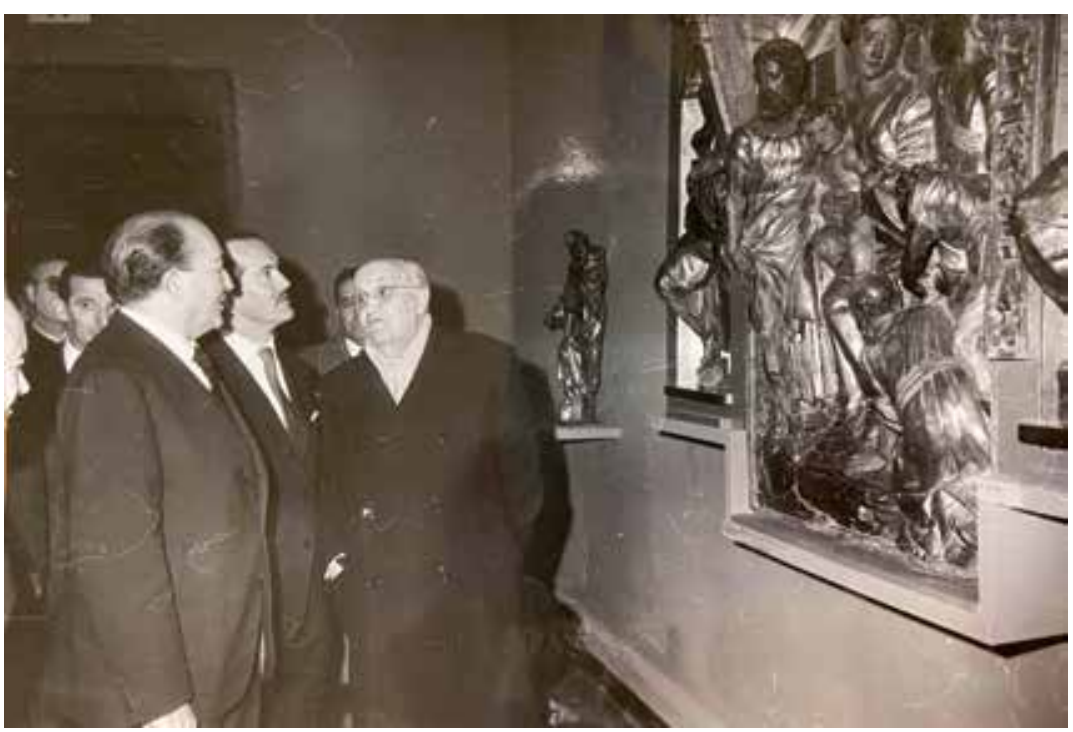

Fig. 5. Gratiniano Nieto Gallo en la inauguración de la exposición Berruguete, diciembre 1961.

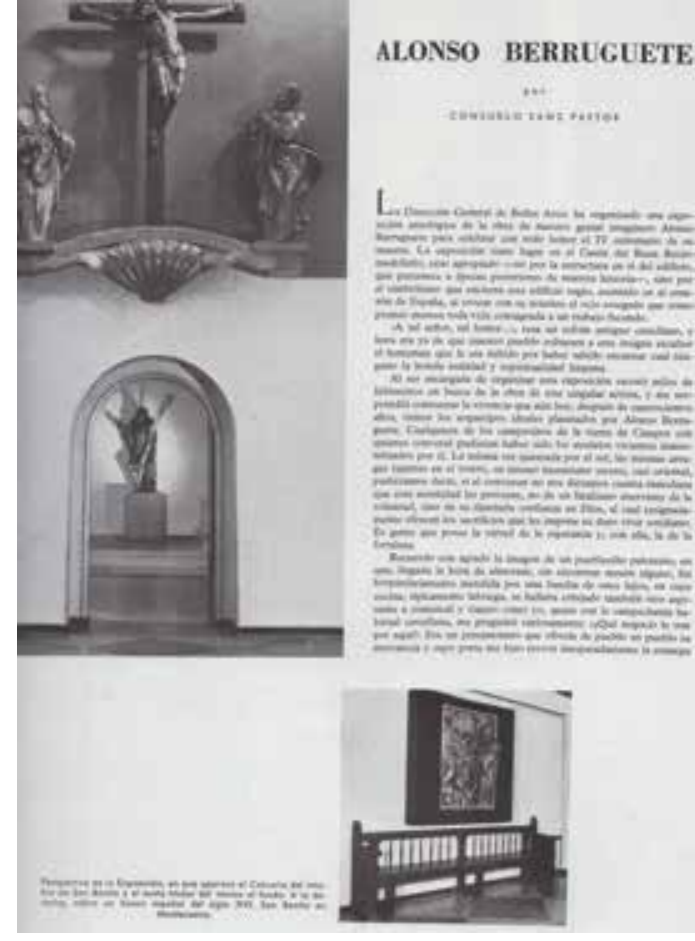

Fig. 6. Consuelo Sanz-Pastor, "Alonso Berruguete". En: Arte $=$ Hogar, 203, febrero 1962, s. p.

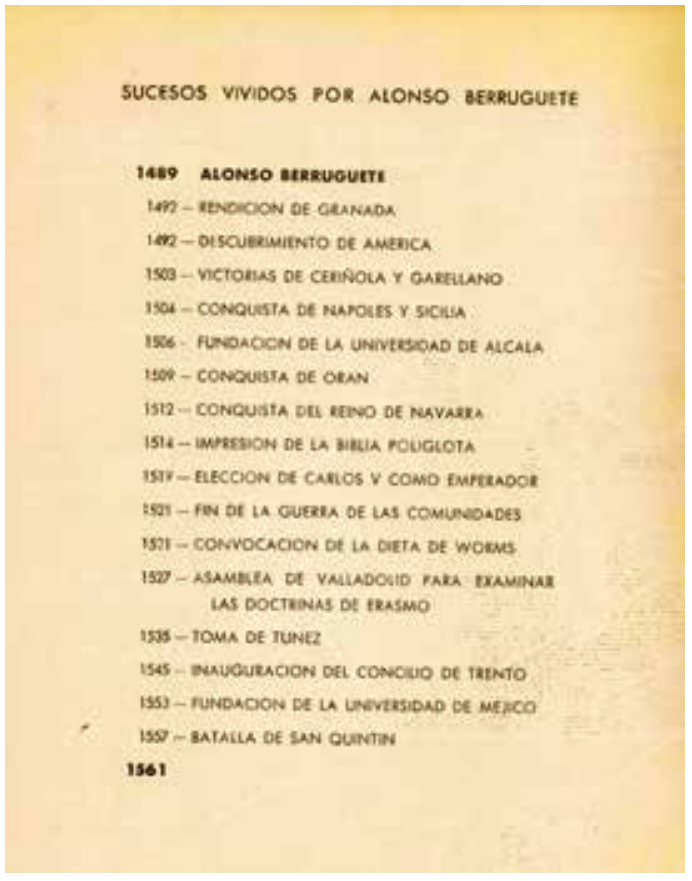

Fig. 7. "Sucesos vividos por Alonso Berruguete". En: Alonso Berruguete. Guía de la Exposición conmemorativa del IV Centenario de su muerte. Madrid, Dirección General de Bellas Artes, 1961.

y De Lasarte. Es decir, la kermesse Pintura Catalana desde la Prehistoria hasta nuestros días, en el contexto de la despótica visión territorial y lingüística del franquismo, podría interpretarse como un intento de reequilibrar la línea descaradamente 'castellana' seguida por las iniciativas anteriores. ${ }^{35}$ Además, al referirse directamente a la Escuela Catalana de Pintura Contemporánea

35 Nieto Gallo, $1962 \mathrm{~b}$. 
(contrastada con las tendencias madrileñas por críticos como Juan-Eduardo Cirlot), ${ }^{36}$ el trasfondo propagandístico de la iniciativa es evidente, incluso en la portada del catálogo que en sus diversas ediciones muestra una obra de Joan Miró, presente en las salas con solo dos gouaches y dos litografías [fig. 8]. De hecho, desde el regreso a la patria del pintor en 1940, el régimen había intentado incluir sus creaciones en incontables iniciativas gubernamentales y el artista había evitado sistemáticamente estos avances, limitándose, por ejemplo, a exhibir una selección de obras gráficas en el pabellón español de la Bienal de Venecia del 1954. ${ }^{37}$

Sin embargo, a pesar del buen éxito de la edición barcelonesa, los papeles ministeriales muestran hasta qué punto se la veía como una improvisación, fruto del fracaso de un proyecto mucho más ambicioso, tanto desde una perspectiva económica como en términos de diplomacia cultural. Ya el 23 diciembre del 1961 los Asuntos Exteriores — presididos por el reformista Fernando María Castiella, que estaba gestionando la entrada de España en importantes instituciones internacionales - habían pedido información técnica sobre los plazos del calendario madrileño y los acuerdos por las concesiones de las obras para organizar "una exposición de las mismas en la Academia Española de Bellas Artes de Roma y en el Colegio de San Clemente de los Españoles de Bolonia". Se suponía que este evento encajaría con el cierre de la exposición del Casón, previendo una cierta diferenciación en los préstamos: desde el inicio de la práctica, el Ministerio había declarado la necesidad de "solicitar a las autoridades italianas el préstamo de las obras de este pintor y escultor existentes en Italia". ${ }^{38}$ Se hace referencia, obviamente, a la biografía de Alonso — que pasó, a principios del siglo XVI, unos años entre Roma y Florencia - pero se debe creer que la burocracia ministerial también tenía en mente el moderno resurgimiento del interés por el catálogo italiano del artista, impulsado por una contribución pionera de Roberto Longhi que apareció en 1953 en la revista Paragone. ${ }^{39}$

Si bien se puede dudar que la dirección de Relaciones Culturales conocía las convincentes atribuciones del académico, por el contrario es creíble que fuera advertida del enfoque más generalizado de los estudios sobre este tema ${ }^{40}$ Sin embargo, es significativo que para la eventual segunda etapa se declarara la necesidad de este tipo de integración. Casi todos los textos publicados en España con motivo del centenario - por ejemplo los artículos publicados en periódicos como $A B C$ o Mundo Hispánico - coinciden en reducir el impacto de la educación florentina de Berruguete, interpretando mayoritariamente su larga estancia como una etapa de la que el escultor supo desprenderse, conservando la propia esencia 'castellana' ${ }^{41}$ Así se expresa Victorio Macho, al prever la instalación del monumento conmemorativo: "Por eso, camino hacia España sólo traería en su imaginación las concepciones miguelangelescas [...]. Bien hizo, el más grande escultor castellano y español de nuestro Renacimiento al abandonar Italia, que sin esta imperiosa decisión [...] no hubiera sido él". ${ }^{42}$ Y la misma perspectiva sigue Sanz-Pastor en el catálogo. ${ }^{43}$

El diseño propagandístico del Ministerio se concreta, además, en una de las pocas reseñas sobre la muestra de Madrid que se publicó en Italia, aparecida en el L'Osservatore Romano del 23 marzo del 1962. De hecho, si bien el artículo llegó tarde para favorecer el cumplimiento de la

\footnotetext{
${ }^{36}$ Véase, por ejemplo, De La Torre, 2011. En: <https://www.delatorrealfonso.com/2011/07/31/de-goya-a-nuestros$\operatorname{dias} />$.

${ }^{37}$ Massot, 2018: 758-763.

${ }^{38}$ AGA, Caja 98481 obs. 695, carta del Director General de Relaciones Culturales, Ministerio de Asuntos Exteriores, al Director General de Bellas Artes, 23 diciembre 1961; Carta del Director General de Bellas Artes al Director General de Relaciones Culturales, Ministerio de Asuntos Exteriores, 25 enero 1962; Carta del Director General de Relaciones Culturales, Ministerio de Asuntos Exteriores, al Director General de Bellas Artes, 14 febrero 1962. Ningún rastro de esta iniciativa se pudo encontrar en el archivo de la Academia de España en Roma. Quiero agradecer a Margarita Alonso Campoy por su disponibilidad.

${ }^{39}$ Longhi, 1953.

${ }^{40}$ Becherucci, 1953; Zeri, 1953; Griseri 1959. Para un recuerdo de los intereses españoles de Longhi en la década de 1950 véase Griseri, 2007.

${ }_{41}$ Véase, por ejemplo, Diego, 1961; Nieto Gallo, 1961c; Nieto Gallo, 1962a.

${ }_{42}$ Macho, 1961: 20-21.

${ }^{43}$ Sanz-Pastor, 1961b: 28.
} 


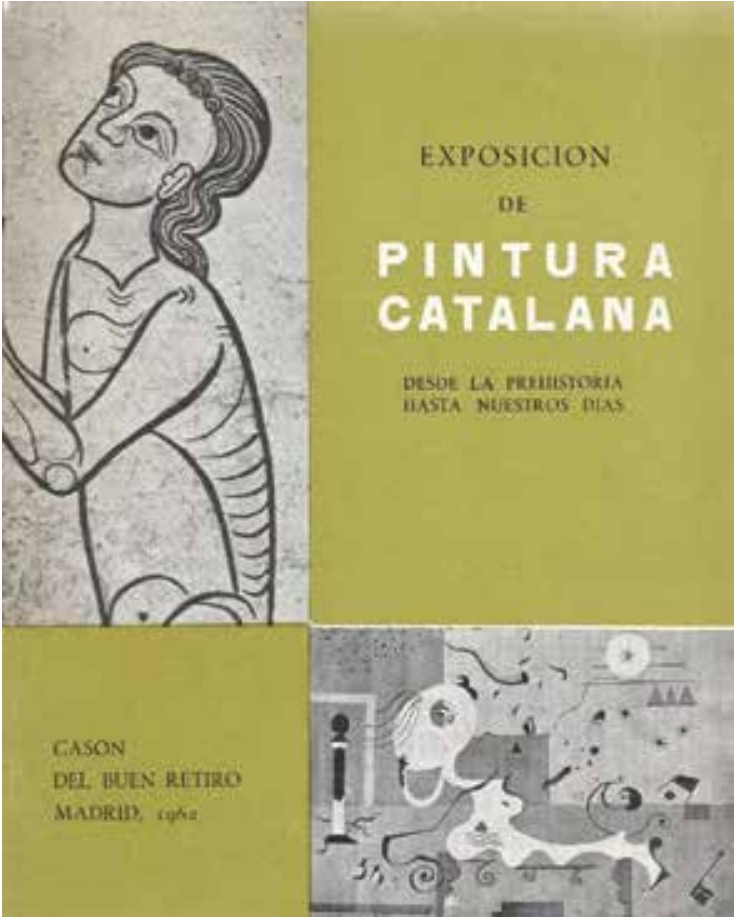

Fig. 8. Pintura catalana desde la Prehistoria hasta nuestros dias. Madrid: Dirección General de Bellas Artes, 1962, portada del catálogo.

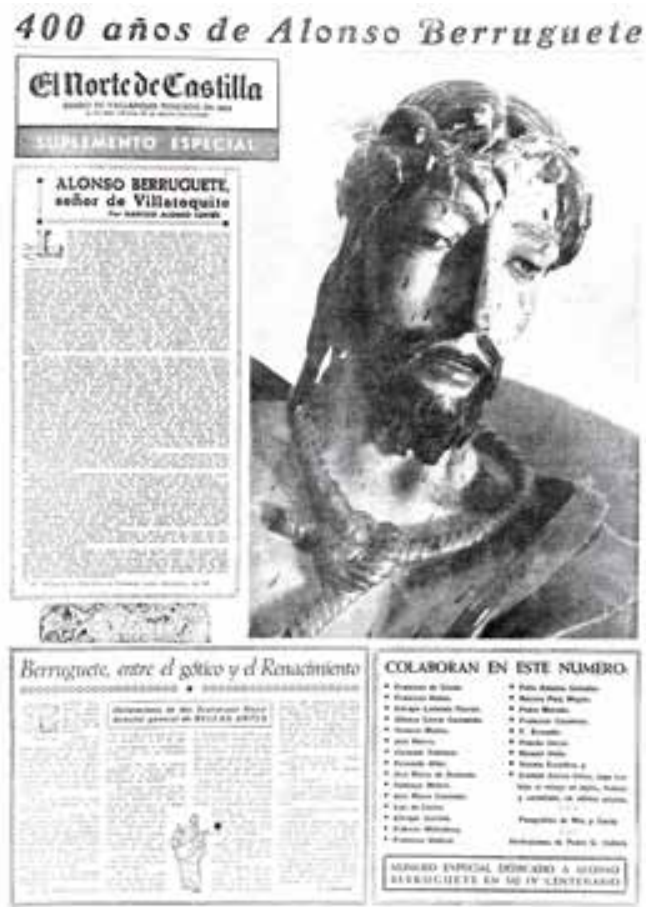

Fig. 9. El Norte de Castilla, Suplemento Especial, 17 diciembre 1961, p. 1.

etapa romana (o boloñesa) del acontecimiento, su contenido — garantizado por un periódico propicio al gobierno franquista, incluso en época preconciliar ${ }^{44}$ — insiste en la función de 'puente' en referencia al escultor, "uno de los fenómenos típicos de la prodigiosa influencia del arte italiano que tantas veces encendió y estimuló el genio artístico español"; ${ }^{45} \mathrm{y}$, como era de esperar, el texto fue enviado puntualmente por el embajador de España ante la Santa Sede, Francisco Gómez de Llano, a Luis Villalba Olaizola, Director General de Relaciones Culturales del Ministerio de Asuntos Exteriores (quien luego informó a Nieto Gallo). ${ }^{46}$

Sin embargo, el inacabado proyecto italiano evoca otras acciones impulsadas por el Ministerio y dirigidas, según una red articulada de contactos, a las embajadas de España en el mundo. En febrero de 1962 se emitió una circular en la que el gobierno instaba a los representantes diplomáticos a promover, en los países de incardinación, el reciente centenario. ${ }^{47}$ Se preparó así un kit para ilustrar la exposición del Casón y la figura de Alonso según la perspectiva crítica dictada por la Dirección General. Además del catálogo, el paquete incluía el especial dedicado al centenario del Norte de Castilla en diciembre del 1961 con aportaciones del mismo Nieto Gallo, de De Cossío, Azcárate, Lafuente Ferrari, Macho y Wattenberg (también implicados en las conmemoraciones de aquel año) [fig. 9]. El número contaba también con las reflexiones de Alfonso Corral Castanedo (Berruguete en la España de Carlos V), Enrique Gavilán (Castilla en Berruguete), Francisco Umbral (Picasso y Berruguete), con explícitas reivindicaciones de la hispanidad del escultor. ${ }^{48}$ En

44 Véase Suárez, 2011: 411-458.

${ }^{45}$ K., 1962.

46 AGA, Caja 98475 obs. 689, carta del Director General de Relaciones Culturales, Ministerio de Asuntos Exteriores, al Director General de Bellas Artes, 13 abril 1962.

47 AGA, 51/15995, Circular n. 37 del Ministerio de Asuntos Exteriores.

48 "400 años de Alonso Berruguete". En: El Norte de Castilla, Suplemento Especial, 17diciembre 1961, Valladolid. El suplemento consta de 12 páginas, ricamente ilustradas con fotografías y dibujos de Pedro G. Collado. 
este contexto, no es de extrañar que un personaje de la fama de Manuel Viola —entrevistado por el diario - afirmase que toda la pintura informal española, de raíz barroca, podría ser considerada de hecho deudora de Berruguete. ${ }^{49}$

El kit ministerial también contenía una serie de diapositivas que ilustraban la obra de Alonso. La intención era solicitar varias presentaciones destinadas a magnificar el eco de la muestra madrileña, subrayando en los diferentes contextos de recepción el valor nacional del artista y su peculiar lenguaje expresivo. Por ejemplo, la invitación fue aceptada por la embajada de Londres, que entre febrero y finales de 1962 se comprometió a dar la publicidad adecuada a la exposición, en colaboración con el Instituto de España: se programó así una conferencia en noviembre, pronunciada por Ernesto La Orden, encargado de Asuntos Culturales. ${ }^{50}$

Ciertamente, esta solicitud debe incluirse en el panorama más amplio de las relaciones renovadas entre España y el Reino Unido, merced a la inserción en el concierto de democracias continentales que el gobierno británico auspició con su posición favorable durante los años cincuenta. Sin embargo, desde un punto de vista similar, parece aún más significativa la campaña dirigida por el Ministerio hacia los países de América Latina, ${ }^{51}$ acción diplomática que no es de extrañar, si se piensa en cómo Mundo Hispánico — periódico fundado para difundir una imagen positiva de España en sus antiguos dominios transoceánicos - había consagrado numerosas páginas a la exposición de Berruguete en el número de enero de $1962 .{ }^{52}$

Por un lado, en una campaña de promoción de este tipo tuvieron un peso específico consideraciones exquisitamente histórico-artísticas. Es decir, se pudo creer que, en el contexto sudamericano, una producción como la de Alonso - autor de expresivas esculturas de madera policromadas, precursoras de la gran imaginería barroca y colonial - tenía la ventaja de un eco distinto. Por otro lado, no debió pesar menos la propaganda dirigida a esas latitudes por el gobierno franquista desde la inmediata posguerra, también conocida como política de la Hispanidad y que pretendía presentar a España como Madre de las Naciones en virtud de su perdurable pasado colonial.

Bastará mencionar aquí, entre los casos más emblemáticos y elocuentes, el lanzamiento de las Bienales Hispanoamericanas de Arte, cuya primera edición se inauguró en Madrid el 12 octubre de 1951, es decir, en el propio Día de la Hispanidad durante el V Centenario desde el nacimiento de Isabel la Católica y Cristóbal Colón. De hecho, el evento ofrecía un escenario importante para promover los vínculos entre Madrid y los antiguos dominios del Imperio, sub specie artis y encubriendo el mensaje propagandístico en los lenguajes universales de la Modernidad. Sujeta a polémicas crecientes a lo largo de los años, la bienal, encomendada al Instituto de Cultura Hispánica, habría hecho escala - según plazos irregulares - también en La Habana en 1954 para luego regresar a Barcelona en 1955. Aún al final de la década, antes de que la iniciativa llegara a un punto muerto definitivo, se intentó planificar una edición en América Latina, identificando inicialmente una posible sede en Caracas y luego, finalmente, convergiendo en Quito, con la idea de aprovechar la concomitancia con la XI Conferencia Interamericana, programada en Ecuador en $1960 .{ }^{53}$

Precisamente este último encuentro internacional ofrece un marco esclarecedor, en términos de mayores contactos diplomáticos, para la lectura de algunos de los documentos encontrados en el Archivo de la Administración. De hecho, sabemos que en junio 1962 Nieto Gallo recibió de los Asuntos Exteriores un despacho del embajador español en Quito, Ignacio de Urquijo y Olano, con un artículo, aparecido en el diario El Comercio del 8 abril del 1962, dedicado al centenario

\footnotetext{
49 Viola, 1961.

${ }^{50}$ AGA, 54/7403, carta del Director General de Bellas Artes a la Embajada de España en Londres, 19 febrero de 1962; carta de Alberto López Herce, encarjado de negocios de la Embajada de España, al Ministro de Asuntos Exteriores, 26 febrero 1962; carta de Alberto López Herce, encarjado de negocios de la Embajada de España, al Ministro de Asuntos Exteriores, 6 marzo 1962; Carta del Director General de Bellas Artes al Embajador de España en Londres, 17 marzo 1962; carta del Director General de Bellas Artes al Embajador de España en Londres, 13 abril 1962; carta del Embajador de España en Londres al Ministro de Asuntos Exteriores, 18 mayo 1962.

51 Delgado Gómez-Escalonilla, 1988.

52 Véase nota 41.

53 Véase Cabañas Bravo, 1996.
} 
de Berruguete por el escritor Augusto Arias, autor entre otras cosas de un fundamental Panorama de la literatura ecuatoriana. ${ }^{54} \mathrm{Al}$ dar cuenta de las aportaciones recogidas en el Norte de Castilla, el texto enfatiza el carácter castellano del arte de Alonso, cuestionando a su vez a Miguel de Unamuno y su concepción del sentimiento trágico de la vida, una línea interpretativa, esta última, que no habría debido trastornar al equipo ministerial, ya que reafirmaba en el fondo los principios inspiradores de la exposición madrileña. ${ }^{55}$

Desde esta misma perspectiva, el diálogo establecido con la embajada de Río de Janeiro parece no ser menos significativo, ya que España y Brasil vivieron, desde fines de la década de 1940, relaciones diplomáticas preferenciales, tras una fase divergente después de la Segunda Guerra Mundial. Además de estrechar los lazos comerciales, tal camaradería política tendría repercusiones en el ámbito cultural, uniendo a los intelectuales de los dos países —entre los gobiernos de Getúlio Vargas y Juscelino Kubitschek de Oliveira - en una red de intercambios recíprocos. Así, en 1952 se inauguró la Casa de Brasil en Madrid, mientras, ya a mediados de la década, de las cuarenta y cinco sucursales americanas gestionadas por el Instituto de Cultura Hispánica, seis tenían su sede en ciudades brasileñas, de São Paulo a Río de Janeiro, incluidas Recife, Salvador, Porto Alegre y Natal. ${ }^{56}$

Este listado de estructuras ayuda a contextualizar los esfuerzos del Ministerio de Asuntos Exteriores. Sabemos que, tras la recepción de la circular de febrero del 1962 emitida por las autoridades de Madrid, el embajador de España en Río, José de Rojas y Moreno, a su vez se puso en contacto con los cónsules de algunos centros más periféricos, recurriendo en particular a aquellos en los que estaban ubicadas las sucursales del Instituto: por ejemplo, se habría dirigido a las representaciones diplomáticas de Salvador y Porto Alegre, así como a la de Santos, refiriéndose al "IV centenario de la muerte del gran escultor castellano Alfonso [sic] Berruguete" y compartiendo con ellas "el interés en dar a conocer sus méritos en el ámbito cultural brasileño". ${ }^{57}$

Al mismo tiempo, Carlos de la Presilla, pintor y a la sazón secretario de embajada en Río, realizaba una amplia campaña de prensa, informando a los principales periódicos y revistas nacionales - de Correio de Manha a Diario Carioca, de Diario de Noticias a O Jornal y O Globo- sobre el aniversario celebrado en Madrid, difundiendo los artículos del Norte de Castilla y sugiriendo que firmas relevantes como Jayme Maurício Rodrigues Siqueira o Antonio Bento de Araujo Lima debiesen ocuparse del tema, para informar al "pueblo brasileño siempre" interesado "por los acontecimientos artísticos tanto nacionales como internacionales". ${ }^{58}$

El consulado de Santos (en el estado de São Paulo) se mostró particularmente receptivo en relación con las directivas ministeriales, pues ya el 11 de mayo se realizó una reunión cultural en el local Elos Club — presentes "las autoridades civiles, militares y eclesiásticas [...], junto con [...] diversas personalidades brasileñas y miembros más destacados de la colonia española"- durante la cual se pronunció la conferencia Vida y obra de Berruguete, compuesta para la ocasión por Manuel Romero García, residente en Brasil pero "licenciado en Ciencias Políticas y Económicas por la Universidad de Madrid". ${ }^{59}$ Adicionalmente, después de unos días, es decir, a mediados de junio, el cercano centro de Itu - en el mismo estado - acogió un evento en la Facultad de Filosofía Ciencias y Letras Nossa Senhora do Patrocínio, durante el cual se presentó una contribución sobre

\footnotetext{
${ }^{54}$ AGA, Caja 98475 obs. 689, carta del Director General de Relaciones Culturales, Ministerio de Asuntos Exteriores, al Director General de Bellas Artes, 26 de mayo de 1962; carta del Director General de Bellas Artes al Director General de Relaciones Culturales, Ministerio de Asuntos Exteriores, 25 junio 1962.

${ }_{55}$ Arias, 1962.

${ }^{56}$ Izepe de Souza, 2017.

${ }^{57}$ AGA, 51/15995, circular n. 19 del Embajador de España, Rio de Janeiro, a los Consulados en Santos, SalvadorBahía y Porto Alegre.

58 AGA, 51/15995.

${ }^{59}$ AGA, 51/15995, carta del Cónsul de Santos al Ministro de Asuntos Exteriores, 12 mayo 1962.
} 
La escultura española del siglo XVI y la obra de Berruguete escrita por Célia Berrettini, académica y traductora del francés e inglés, también licenciada en España antes de su traslado a Brasil. ${ }^{60}$

No disponemos de los textos de las conferencias, que se han podido ceñir a los materiales enviados por el Ministerio de Madrid. Sin embargo, el fondo ideológico de los hechos —en cierta medida sugerido por el valor cultural y educativo de los oradores - se pone de relieve gracias a lo ocurrido en la ciudad de Porto Alegre en la ocasión de una cita similar. A principios de mayo, el Instituto de Cultura Hispánica de la ciudad presentó algunas intervenciones destinadas a perfilar la figura de Alonso a una amplia audiencia de espectadores; luego, el consulado convenció al Instituto de Bellas Artes de unirse a las conmemoraciones, con una conferencia que originalmente debía ser pronunciada en mayo y que, por razones logísticas, fue aplazada al mes de octubre. En este caso, el discurso estuvo a cargo de Fernando Corona: escultor y arquitecto español nacido en Vitoria en 1895 y trasladado a Brasil en 1912, nombrado profesor del Instituto en 1938 para la cátedra de Escultura y Modelado, su exitosa carrera le había permitido caracterizar el mapa urbano de Porto Alegre con construcciones importantes, como la Galería Chaves y el Edificio Colonial. ${ }^{61}$

Es una lástima que el texto del discurso del 1962 no se pudiera localizar entre los papeles que se guardan en la biblioteca del Instituto donde el artista fue profesor; ${ }^{62}$ y ni tan siquiera Corona lo incluyó en su colección de artículos titulada Caminhada nas artes 1940-76, publicada a finales de los años setenta, quizás por el valor demasiado ocasional de la lección sobre Berruguete. ${ }^{63}$ En cualquier caso, habría sido interesante sopesar las preocupaciones planteadas en el cuerpo diplomático español por el encargo recibido por el arquitecto, en un contexto que escapó claramente al control del consulado. De hecho, la preocupación de Álvaro Raya Ibáñez, vicecónsul de Porto Alegre, fue poner al día al embajador en Río con una carta fechada el 23 de octubre, solo cinco días después de la conferencia, garantizando, por un lado, el éxito de la iniciativa y tranquilizando, por el otro, al funcionario sobre el tenor de la lección: "el trabajo presentado [...] por el profesor Corona fue muy completo y situó al personaje en el ambiente artístico de la época, la influencia recibida de él y describió el momento político imperante con la mayor propiedad y en forma recta y plenamente ajustada a la ortodoxia histórica". Una insistencia similar se explica por la continuación del mensaje:

El conferenciante, [...] es español de nacimiento y está personalmente vinculado, en razón de fuertes convicciones políticas, a corrientes nada favorables en ese campo de España. [...]. Destacado, en presencia del que suscribe, por la Directora del Instituto de Bellas Artes, para la misión de pronunciar una conferencia sobre Berruguete, aceptó en el acto. La postura de este consulado fue la de dar plena conformidad y de celebrar la indicación. El que suscribe se percató en seguida que una ocasión favorable se presentaba para dejar de manifestó que no se suele hacer distinciones por razón de pensamientos, confiando además que, de esa circunstancia, se derivarían consecuencias favorables, como así lo habrá podido comprobar V.E. en la referencia que antecede, sobre la forma en que fue conducida la conferencia. ${ }^{64}$

En definitiva, esta historia pone de manifiesto no solo el juego de intereses que promovió el centenario de Berruguete, sino también las razones políticas que sustentaban la incansable promoción realizada por el gobierno central en relación a esta efeméride.

Además, en los años sesenta el perfil de Alonso para los estudios histórico-artísticos era el de una personalidad poco conocida por la literatura extranjera (con la única excepción de Italia), cuya profundización, incluso en la propia patria, había coincidido con la dolorosa mitad de siglo vivido por España entre el reinado de Alfonso XIII y el gobierno totalitario del Caudillo. Se trata de un

\footnotetext{
${ }^{60}$ AGA, 51/15995, carta del Cónsul General de San Pablo al Ministro de Asuntos Exteriores, 20 junio 1962.

${ }_{61}^{61}$ AGA, 51/15995, Carta del Vicecónsul encargado de Porto Alegre al Embajador de España, Río de Janeiro, 6 julio

${ }^{62}$ Quiero agradecer a Carmen Valenti del Arquivo Histórico do Instituto de Artes.

${ }^{63}$ Corona, 1977.

${ }^{64}$ AGA, 51/15995, carta del Vicecónsul encargado de Porto Alegre al Embajador de España, Río de Janeiro, 23 octubre 1962.
} 1962. 
periodo en el que las lecturas modernas centradas en su producción — por ejemplo, la ofrecida por Ricardo de Orueta y germinada dentro de la Institución Libre de Enseñanza, en la primera monografía del siglo XX sobre Alonso - se habían visto sometidas al escrutinio de una creciente ideologización patriótica, destinada a servir a la misión cultural del franquismo. En este sentido, la figura del genial imaginero, dedicada a tallar los pinos de Castilla, empeñada únicamente en la laboriosa construcción de inmensos retablos, se adaptó exactamente a la imagen del "artista creyente de pueblo creyente", al medallón del "artista español en todos los sentidos", muy útil para la causa del nacionalcatolicismo. Por eso mismo, por tanto, el régimen - en un momento en que los lazos de la represión política se aflojaban gracias a la concertación de una astuta política exterioraprovechó la ineludible oportunidad de la conmemoración de 1961 para exaltar su propia idea de 'estado' a través de las obras de un escultor que parecía simbolizar la misión trans-histórica de España tanto en el plano biográfico como en el más universal de las formas.

Tal proyecto, además, se reinsertó extensamente en el uso que en esos años el Ministerio de Educación Nacional estaba haciendo del renovado Casón del Buen Retiro, lugar que se había afianzado en las intenciones de la administración como panteón para celebrar las glorias artísticas nacionales bajo la égida de la dictadura.

Así, a las ya mencionadas exposiciones de Velázquez y Goya seguirían - tras la de Berruguete y además de la exhibición dedicada a Cataluña - una monográfica de Joaquín Sorolla ${ }^{65}$ y otra de Francisco de Zurbarán, ${ }^{66}$ mientras que hacia el final de la década las salas del Casón albergarían eventos excéntricos (pero no menos significativos en términos de propaganda) sobre la historia de la artillería y la figura de Santa Teresa. ${ }^{67}$

Esta serie de iniciativas no marcó un punto de inflexión en la política cultural del régimen, más bien continuando en una línea española para el arte moderno y contemporáneo según una corriente interpretativa con una clara impronta tradicionalista y un espíritu patriótico, alimentados por la religiosidad ortodoxa, el imaginario imperial y el folclore 'eterno'. Para demostrar tal continuidad bastará mencionar muestras o eventos anteriores, celebrados desde el final de la Guerra Civil, como el Salón Imperial de la exposición de Ginebra de 1939, preparado con los tesoros del Prado en ese momento alojados en Suiza; ${ }^{68}$ o la impresionante monográfica de Zuloaga en el Museo de Arte Moderno de Madrid en 1941; o, también —aunque en un nivel menos impactante—- la II Exposición de Estampas de la Pasión, que se realiza al año siguiente en la Central Nacionalsindacalista Provincial de la misma ciudad, asociando creaciones de artistas como José Benlliure o Francisco Palma Burgos "obras de Juni, Montañes, Salzillo, el Greco". 69

La programación del Casón, sin embargo, si bien confirmaba presupuestos ideológicos totalmente consonantes, llevó sus consecuencias en términos de calendario y propuesta cultural hacia una organicidad y coherencia hasta ese momento apenas alcanzadas, destinando al mismo tiempo las iniciativas allí organizadas a un escaparate cosmopolita y turístico con efectivo impacto internacional, bajo la guía oficial de la Dirección general de Bellas Artes y del Ministerio de Asuntos Exteriores: perspectiva que garantizó también a la imponente exposición Berruguete una gran centralidad a nivel de la propaganda del franquismo, en perfecta sintonía con estas premisas doctrinales.

\section{BIBLIOGRAFÍA}

Álvarez Casado, Ana Isabel (2003): Bibliografía artística del franquismo: publicaciones periódicas, 1936-1948. Madrid: Universidad Complutense de Madrid.

Álvaro, Francisco (1962): “Los actos de homenaje a Berruguete en Valladolid”. En: $A B C, 13$ febrero, Madrid, p. 39.

\footnotetext{
65 Pantorba, 1963.

66 Caturla, 1964

67 Exposición Historia de la artillería. Madrid, Casón del Buen Retiro, 1966; Camón Aznar, 1971.

68 Colorado Castellary, 2008: 297-310.

69 Ureña Portero, 1981: 102.
} 
Arias, Augusto (1962): “Cuarto Centenario de Berruguete”. En: El Comercio, 8 abril, Quito, tercera sección, p. 4.

Bandera, Maria Cristina (1999): Le prime Biennali del dopoguerra. Il carteggio Longhi-Pallucchini. Milano: Edizioni Charta.

Barrios Felipe, Maximiliano (2017): "Victorio Macho y su escultura de Berruguete". En: Patrimonio histórico de Catilla y León, 60, pp. 56-57.

Becherucci, Luisa (1953): “Note brevi su inediti toscani”. En: Bollettino d'arte, s. IV, XXXVIII, Roma, pp. 168-169.

Brasas Egido, José Carlos (1987): "Victorio Macho y Alonso Berruguete: comentarios sobre una huella artística y vicisitudes de un monumento conmemorativo". En: Actas del I Congreso de Historia de Palencia. Palencia: Diputación provincial, I, pp. 251-272.

Cabañas Bravo, Miguel (1996), La política artística del franquismo: el hito de la Bienal Hispano-americana. Madrid: Consejo Superior de Investigaciones Científicas.

Camón Aznar, José (ed.) (1971): Santa Teresa y su tiempo. Madrid: Dirección General de Bellas Artes.

Caturla, Maria Luisa (ed.) (1964): Exposición Zurbarán en el III centenario de su muerte. Madrid, Dirección General de Bellas Artes.

Chueca Goitia, Fernando/Navascués Palacio, Pedro (2004): "El Casón del Buen Retiro". En: El Casón del Buen Retiro, remodelación y ampliación. Madrid: FCC Construcción, S.A. Necso, pp. 9-41.

Colorado Castellary, Arturo (2008): Éxodo y exilio del arte. La odisea del Museo del Prado durante la Guerra Civil. Madrid: Cátedra.

Corona, Fernando (1977): Caminhada nas artes 1940-76. Porto Alegre: Editora Meridional Emma.

Torre, Alfonso de la (2011): "De Goya a nuestros días". En: < https://www.delatorrealfonso.com/2011/07/31/de-goya-anuestros-dias/>.

Sambricio, Valentín de (ed.) (1961): Exposición Francisco de Goya. IV centenario de la Capitalidad del Ayuntamiento de Madrid. Madrid: Dirección General de Bellas Artes.

Delgado Gómez-Escalonilla, Lorenzo (1988): Diplomacia franquista y la política cultural hacia Iberoamérica 19391953. Madrid: Consejo Superior de Investigaciones Científicas.

Diego, Gerardo (1961): “Berruguete, excepción”. En: $A B C, 10$ diciembre, Madrid, s. p.

Di Martino, Enzo (2005): The History of the Venice Biennale 1895-2005. Venezia: Papiro Arte.

Flores, A. (2005): “Entrevista a Consuelo Sanz-Pastor Fernández de Piérola”. En: Museos, 1, 2005, pp. 174-183.

Gallego Burín, Antonio (1960): premisa. En: Lafuente Ferrari, Enrique (ed.): Velázquez y lo velazqueño. Madrid: Dirección General de Bellas Artes, pp. 7-9.

Gallego Morell, Antonio (1973): Antonio Gallego Burín. Madrid: Editorial Moneda y Crédito.

Gaya Nuño, Juan Antonio (1961): "La exposición de Goya en el Casón”. En: Blanco y negro, 2579, 7 octubre, Madrid, s. p.

Griseri, Andreina (1959): "Nuove schede di manierismo iberico". En: Paragone-Arte, 113, Florencia, pp. 33-43.

Griseri, Andreina (2007): "Madrid, aprile 1954, Longhi è qui". En: Gregori, Mina / Romano, Giovanni (eds.): La collezione di Roberto Longhi. Dal Duecento a Caravaggio, a Morandi. Savigliano: L'Artistica Editrice, 2007, pp. 29-38.

Gutiérrez-Solana, José (1920): La España negra. Madrid: Beltrán.

Hernández Burgos, Claudio (2011a): "La construcción ideológica de un franquista: Antonio Gallego Burín”. En: Barrio Alonso, Ángeles / De Hoyos Puente, Jorge / Saavedra Arias, Rebeca (eds.): Nuevos horizontes del pasado. Culturas políticas, identidades y formas de representación. Santander: PubliCan Ediciones, p. 75.

Hernández Burgos, Claudio (2011b): "El largo camino hacia el franquismo. Antonio Gallego Burín (1915-1939)”. En: Revista del Centro de Estudios Históricos de Granada y su Reino, 23, Granada, pp. 193-206.

Hernández Díaz, José (ed.) (1960): Exposición Homenaje a Velázquez en el III centenario de su muerte. Sevilla: Museo Nacional de Bellas Artes.

Historia de la artillería (1966): Exposición Historia de la artillería. Madrid, Casón del Buen Retiro.

Izepe de Souza, Ismara (2017): "Entre el discurso modernizado y la propaganda hispanista. Instrumentos y posibilidades de la dimensión cultural de las relaciones hispano-brasileñas (1950-1960)”. En: Res Gesta, 53, Rosario, pp. 80-99.

Izquierdo, Antonio (1961): “Cien Goyas en el Casón del Buen Retiro". En: Panorama. Suplemento dominical de Arriba, 8 octubre, Madrid, s. p.

Jiménez-Blanco, Maria Dolores (2001): "Un siglo de política oficial de Bellas Artes a través de la historia de un museo". En: Álvarez Lázaro, Pedro (ed.): Cien años de educación en España. En torno a la creación del Ministerio de Instrucción Pública y Bellas Artes. Madrid: MEC.

K. (1962): "Una grande esposizione nel centenario di Berruguete a Madrid". En: L'Osservatore romano, 23 marzo, Roma, p. 7.

Longhi, Roberto (1953): “Comprimarj spagnoli della maniera italiana”. En: Paragone-Arte, 43, Firenze, pp. 3-15.

Lorente Junquera, Manuel (1960): “El Casón del Buen Retiro, sede de la exposición”. En: Lafuente Ferrari, Enrique (ed.): Velázquez y lo velazqueño. Madrid: Dirección General de Bellas Artes, pp. 21-25.

Macho, Victorio (1961): Berruguete, Prólogo de Teófilo Ortega, Palencia: Edición de la Caja de Ahorros.

Marzo, Jorge Luis / Mayayo, Patricia (2015): Arte en España (1939-2015): ideas, prácticas, politicas. Madrid: Cátedra.

Massot, Josep (2018): Joan Miró. El nen que parlava amb els arbres. Barcelona: Galàxia Gutenberg.

Mena de la Cruz, Juan (1999): Palencia y Victorio Macho (Encuentros Palentinos). Madrid: Caja España.

Mozzati, Tommaso (2021): "Celebrating Alonso Berruguete: Art History and the Spanish Identity, before and after the Civil War”. En: Sculpture Journal, XXXX, 1, 2021, pp. 53-70. 
Muñoz Soro, Javier (2006): “Joaquín Ruiz-Giménez o el católico total: apuntes para una biografía política y intelectual hasta 1963”. En: Pasado y Memoria. Revista de Historia Contemporánea, 5, pp. 259-288.

Nieto Gallo, Gratiniano (1961a): "Alonso Berruguete". En: Sanz-Pastor, Consuelo (ed.): Alonso Berruguete. Guía de la exposición conmemorativa del IV Centenario de su muerte. Madrid: Dirección General de Bellas Artes, pp. 11-16.

Nieto Gallo, Gratiniano (1961b): "Otra notable exposición en puerta: la de Alonso Berruguete. El Director General de Bellas Artes anuncia una gran muestra de pintura catalana”. En: La Vanguardia española, 14 diciembre, Barcelona, p. 11.

Nieto Gallo, Gratiniano (1961c): "Berruguete y su personalidad". En: $A B C, 10$ diciembre, Madrid, s. p..

Nieto Gallo, Gratiniano (1962a): “Berruguete, clasico y baroco”. En: Mundo Hispánico, 166, Madrid, pp. 26-29.

Nieto Gallo, Gratiniano (1962b): premisa. En: Cid Priego, Carlos / Ainaud de Lasarte, Juan (eds.): Exposición de pintura catalana desde la prehistoria hasta nuestros días. Madrid: Dirección General de Bellas Artes, pp. 4-7.

Pantorba, Bernardino de (ed.) (1963): Sorolla 1863-1963. Madrid: Dirección General de Bellas Artes.

Perucho, Joan (1962): “Alonso Berruguete”. En: Destino, XXVI, 1289, 21 abril, Barcelona, p. 49.

Pombo Angulo, Manuel (1961): "El contacto del pueblo con los grandes maestros". En: La Vanguardia española, 19 diciembre, Barcelona, p. 7.

Rosendorf, Neal M. (2014): Franco sells Spain to America. Hollywood, Tourism and Public Relations as Postwar Spanish Soft Power. New York: Palgrave.

Rubio García-Mina, Jesús (1961): "Orden de 6 de mayo de 1961". En: Boletín Oficial del Estado, 127, mayo 1961, Madrid, p. 8102.

Santos Torroella, Rafael (1960): premisa. En: Santos Torrorella, Rafael (ed.), Homenaje informal a Velázquez (O Figura, 1). Barcelona: Graficas Layetana.

Sanz-Pastor, Consuelo (ed.) (1961a): Alonso Berruguete. Guía de la exposición conmemorativa del IV Centenario de su muerte. Madrid: Dirección General de Bellas Artes.

Sanz-Pastor, Consuelo (1961b): "Significado de su arte". En: Sanz-Pastor, Consuelo (ed.): Alonso Berruguete. Guía de la exposición conmemorativa del IV Centenario de su muerte. Madrid: Dirección General de Bellas Artes, pp. 25-31.

Sanz-Pastor, Consuelo (1962): “Alonso Berruguete”. En: Arte=Hogar, 203, Madrid, s. p.

Suárez, Luis (2011): Franco y la iglesia. Madrid: Homolegens.

Ureña Portero, Gabrile (1981): "La escultura franquista, espejo del poder". En: Bonet Correa, Antonio (ed.): Arte del franquismo. Madrid: Cátedra, pp. 77-112.

Viñes Millet, Cristina (2003): Antonio Gallego Burín. Granada: Editorial Comares.

Viola, Manuel (1961): "Berruguete, visto por un abstracto". En: El Norte de Castilla, Suplemento especial, 17 diciembre, Valladolid, p. 11.

Zeri, Federico (1953): “Alonso Berruguete: Una Madonna con San Giovannino”. En: Paragone-Arte, 43, Florencia, pp. 49-51.

Fecha de recepción: 31-VIII

Fecha de aceptación: 11-XI-2020 